\title{
INSTALAÇÃO DE FORNO PARA ENSAIOS DE REDUTIBILIDADE (RI) E DESINTEGRAÇÃO APÓS REDUÇÃO À BAIXA TEMPERATURA (RDI)*
}

\section{Resumo}

Danielle Gonçalves Campos ${ }^{1}$ Gabrielli Machado Otero Fonseca ${ }^{2}$ Helder Machado Correia ${ }^{3}$

Reinaldo Carvalho de Oliveira ${ }^{4}$

Com o ensaio de RDI (Índice de Degradação sob Redução), pode-se determinar a geração de finos durante a redução da carga metálica no alto-forno, e com o RI (Índice de Redutibilidade) determina-se a capacidade do sínter em ceder oxigênio para o gás redutor. São ensaios de extrema importância, pois com o RDI é possível medir a degradação do sínter quando submetido a condições redutoras do alto-forno, e com o $\mathrm{RI}$ entende-se o grau de redução da carga metálica momentos antes do início de seu processo de amolecimento. Com a instalação deste forno no Laboratório de Redução da CSN, será possível correlacionar os componentes do sínter, e de outras cargas metálicas, avaliando suas influências no produto, e, consequentemente, em suas utilizações no alto-forno.

Palavras-chave: Ensaio; RI; RDI; Minério.

\section{FURNACE INSTALLATION FOR TESTING OF REDUCIBILITY (RI) AND LOW-} TEMPERATURE REDUCTION-DISINTEGRATION INDICES (RDI)

\section{Abstrat}

With the RDI test (Low-Temperature Reduction-Disintegration Indices), it's possible to determine the fines generation during the reduction of the metal charge in the blast furnace, and, with RI test (Reducibility Index) determines the capacity of the sinter in giving oxygen to the reducing gas. These tests are extremely important because with RDI it's possible to measure the sinter degradation when subjected to reducing conditions of the blast furnace, and $\mathrm{RI}$ refers to reduction degree of the metal load moments before the start of the softening process. With the installation of this furnace in CSN's Reduction Laboratory, it will be possible correlate the sinter's components, and other metallic fillers, evaluating its influences on the product, and hence their use in the blast furnace.

Keywords: Analysis; RI; RDI; Ore.

1 Engenheira Química, Engenheira de Desenvolvimento, Gerência Geral de Processos Siderúrgicos, CSN, Volta Redonda, RJ, Brasil.

2 Técnica Metalúrgica, Técnica de Desenvolvimento, Gerência Geral de Processos Siderúrgicos, CSN, Volta Redonda, RJ, Brasil.

3 Técnico em Eletrônica, Técnico de Desenvolvimento, Gerência Geral de Processos Siderúrgicos, CSN, Volta Redonda, RJ, Brasil.

4 Técnico Metalúrgico, Supervisor, Gerência Geral de Processos Siderúrgicos, CSN, Volta Redonda, RJ, Brasil. 


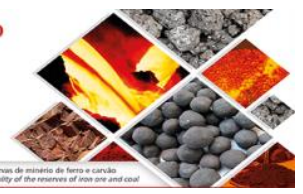

\section{INTRODUÇÃO}

\subsection{Objetivo}

O objetivo deste trabalho é a instalação de forno para ensaios de RI/RDI, a fim de permitir a análise do comportamento dos minérios de ferro na zona de preparação do alto-forno quanto à redutibilidade e a consequente geração de finos.

Com a instalação deste forno no Laboratório de Redução da CSN, será possível correlacionar os componentes do sínter, e de outras cargas metálicas, avaliando suas influências no produto, e, consequentemente, em suas utilizações no alto-forno.

\section{REVISÃO DA LITERATURA}

\subsection{Sínter}

A produção de sínter para altos-fornos a carvão vegetal exige cuidados adicionais, pois de acordo com Dawson (1993b), para que o sínter tenha características adequadas de redutibilidade e boa resistência a degradação, o seu índice de basicidade (relação $\mathrm{CaO} / \mathrm{SiO} 2$ ) deve ser maior ou igual a 1,8, o que é incompatível com a basicidade praticada em altosfornos a carvão vegetal. Nestes fornos a basicidade fica bem abaixo de 1,0 para facilitar a remoção de álcalis, que são introduzidos pelo próprio carvão vegetal [1].

Tal diferença entre os índices de basicidades acarretará num grande volume de escória, o que é indesejável para a sua boa operação. Tal problema não é relevante no uso de pelotas, pois estas podem ser produzidas com basicidade na faixa de 0,33 a $0,78 \mathrm{com}$ boas propriedades físicas e metalúrgicas [2]. No entanto, devido aos custos de concentração do pellet feed e do processo de pelotização, as pelotas são mais caras quando comparadas ao sínter e ao minério granulado [3].

Dessa forma, verifica-se a necessidade da determinação de uma nova composição para a carga metálica que irá alimentar os altos-fornos a carvão vegetal, na qual o sínter terá o papel mais importante. E para o uso deste, necessita-se determinar o valor mínimo de sua basicidade de forma a atender os requisitos de redutibilidade, resistência à degradação e quantidade de escória gerada [4].

\subsection{Processos de Aglomeração}

Durante as primeiras décadas do século $\mathrm{XX}$, os desenvolvimentos dos altos-fornos eram basicamente melhorias no que já estava bem estabelecido. Porém, grandes avanços foram feitos na preparação do minério de ferro, através da aglomeração destes. Finos de minério de ferro não podem ser utilizados diretamente no alto-forno, devido ao processo de contracorrente no qual os sólidos descem contra o fluxo gasoso ascendente. Se os finos fossem carregados diretamente no alto-forno, a permeabilidade da carga seria reduzida dificultando a passagem dos gases e a operação do alto-forno. Embora muitas tentativas e investimentos têm sido tentadas, pesquisando-se rotas inovadoras, por vezes radicais, para o processamento destes finos, até o presente momento, nenhuma delas foi aprovada e consagrada em caráter industrial [5].

A aglomeração continua sendo largamente usada destacando-se os processos de sinterização e pelotização [6,7]. Enquanto nos altosfornos a carvão vegetal a carga ferrosa é constituída tipicamente por minério de ferro granulado, nos altos-fornos a

* Contribuição técnica ao 44은 Seminário de Redução de Minério de Ferro e Matérias-primas, $15^{\circ}$ Simpósio Brasileiro de Minério de Ferro e 2ํㅗ Simpósio Brasileiro de Aglomeração de Minério de Ferro, 15 a 18 de setembro de 2014, Belo Horizonte, MG, Brasil. 


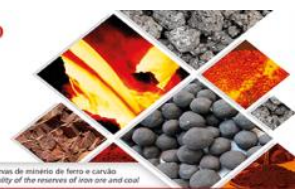

coque a carga ferrosa principal é o sínter [8], na faixa de 65 a $85 \%$. O restante é composto por minério de ferro granulado e ou pelotas [3]. A quantidade de sínter é limitada por sua basicidade, normalmente em torno de 1,8, que causa o aumento da quantidade de escória no alto-forno. $O$ uso de minério granulado é interessante pelo seu menor custo, mas está condicionado a sua disponibilidade. A Tabela 1 mostra a carga metálica típica de altos-fornos em várias regiões do mundo.

Tabela 1 - Carga metálica usada em altos-fornos [5]

\begin{tabular}{r|c|c|c}
\hline \hline PAÍS & $\%$ SÍNTER & $\begin{array}{c}\text { \% Minério } \\
\text { Granulado }\end{array}$ & \% PELOTA \\
\hline EUA & $\mathbf{1 0}$ & $\mathbf{3}$ & $\mathbf{8 7}$ \\
\hline Países Europeus & $\mathbf{6 5}$ & $\mathbf{1 5}$ & $\mathbf{2 0}$ \\
\hline Japão & $\mathbf{7 5}$ & $\mathbf{2 0}$ & $\mathbf{5}$ \\
\hline China & $\mathbf{7 5}$ & $\mathbf{1 9}$ & $\mathbf{6}$ \\
\hline Brasil (altos-fornos a carvão vegetal) & $\mathbf{0}$ & $\mathbf{1 0 0}$ & $\mathbf{0}$ \\
\hline Brasil (integradas) & $\mathbf{7 5}$ & $\mathbf{2 0}$ & $\mathbf{6}$ \\
\hline
\end{tabular}

\subsection{O Processo de Sinterização}

O processo de sinterização consiste em aglomerar, por fusão incipiente, uma mistura de finos, porém não tão finos [9], de minério de ferro, de coque ou de carvão vegetal, de fundentes, de sínter de retorno e água.

O sínter de retorno compreende os finos gerados durante o processo de sinterização. Além destes materiais, resíduos portadores de ferro, carbono ou cal podem ser sinterizados.

A adição de água é fundamental na formação e crescimento das quase-partículas, pois gera uma tensão superficial que mantém os grãos coesos, denominada de tensão neutra. No entanto esta não é suficiente para manter a coesão das partículas devido a densidade destas e também pela evaporação da água durante o processo de sinterização.

Portanto, aglomerantes precisam ser adicionados com o objetivo de aumentar a viscosidade da fase líquida dentro dos capilares e propiciar o aparecimento de pontes cerâmicas ou na formação de cálcio-ferritas [10].

Especial atenção deve ser dada as partículas de minério de ferro, conhecidas como sínter feed, que podem ser classificadas como supergrossas, nucleantes, intermediárias, aderentes e superfinas. As partículas supergrossas, intermediárias e superfinas devem ser minimizadas na composição da mistura.

As supergrossas não apresentam a capacidade de aderir às partículas mais finas ao redor e não contribuem para o fenômeno de microaglomeração. Já as partículas intermediárias não se comportam nem como nucleantes e nem como aderentes. Por último, as superfinas causam a perda de permeabilidade do leito de sinterização [11], mas podem ser usadas desde que estas passem por um processo de micropelotização [12].

Os materiais que serão sinterizados são armazenados em silos de onde são extraídos, pesados e conduzidos até um tambor que faz a mistura destes com a adição de água. $\mathrm{O}$ ar é sugado na parte de baixo da carga. Uma vez iniciada a ignição na parte superior, a combustão prossegue à medida que o ar entra em contato com as partículas de coque ou carvão vegetal, formando uma frente de combustão [7].

* Contribuição técnica ao 44 Seminário de Redução de Minério de Ferro e Matérias-primas, $\quad 15^{\circ}$ Simpósio Brasileiro de Minério de Ferro e 2ํㅗ Simpósio Brasileiro de Aglomeração de Minério de Ferro, 15 a 18 de setembro de 2014, Belo Horizonte, MG, Brasil. 

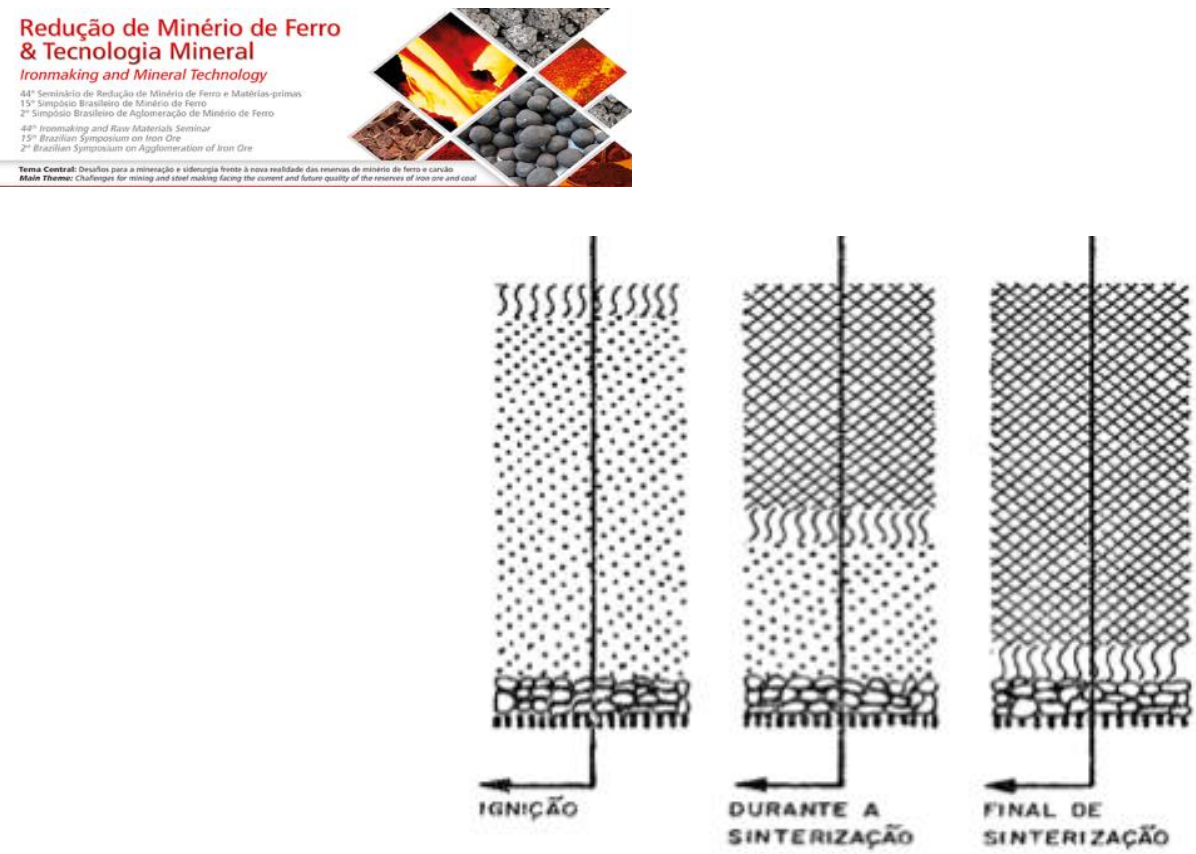

Figura 1 - Ignição e movimentação da frente de combustão durante a sinterização [7].

Após o processo de sinterização, o material obtido é quebrado e classificado em peneiras. Os finos são devolvidos ao silos de matéria-prima para sofrerem nova sinterização, enquanto que o sínter é disponibilizado para ser usado no alto-forno.

A temperatura de sinterização é uma variável importante e deve ser tal que seja capaz de provocar a fusão parcial e produzir uma porção de material fundido, que, durante o resfriamento, irá cristalizar ou solidificar em várias fases minerais que fará a ligação da estrutura do sínter. O perfil do aquecimento tem um significante impacto no tipo de sínter produzido e nas suas propriedades físicas e metalúrgicas.

Outros fatores, que também afetam o processo e a qualidade do sínter [13] são:

(i) O tamanho e composição das micro-pelotas ou grânulos;

(ii) A análise química e granulometria da matéria-prima;

(iii) A composição mineral dos minérios;

(iv) A proporção relativa de minério de ferro, fundentes e coque utilizado na mistura.

\subsection{Degradação Sob Redução (RDI)}

Este fenômeno surge a partir da baixa temperatura de redução da hematita e, como é de se esperar, está relacionado com a quantidade de hematita presente no sínter, ou mais precisamente das particulares formas de hematita. Já a algum tempo, no Japão, vem se acreditando que sínteres com maior quantidade de hematita secundária romboédrica esqueletiforme estão sujeitos a maior RDI [13]. No entanto, Loo et al. [13], a partir do estudo individual de cada fase mineral e da composição mineral do sínter, determinaram uma forte evidência que o RDI está relacionado a propagação de trincas (Figura 2). Como a propagação de trincas diminui com o aumento da porosidade, os poros atuam como obstáculos a propagação de trincas. 


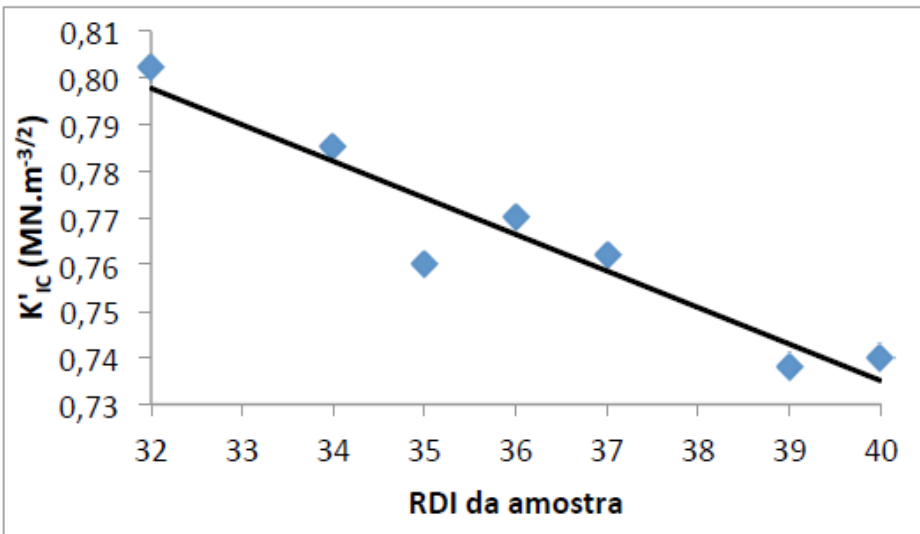

Figura 2 - Tenacidade à fratura de um compósito, a partir das fases minerais do sínter, como função do RDI [13].

A presença de $\mathrm{MgO}$ no sínter traz um efeito benéfico no RDI, pois aumentando-se a quantidade de $\mathrm{MgO}$, mais magnetita será gerada no sínter, e por conseguinte menos hematita. Como a magnetita sofre menos redução a baixas temperaturas, menor será o RDI [4].

\subsection{Redutibilidade}

A redutibilidade está relacionada à estrutura mineral e a porosidade do sínter.

A redutibilidade das fases minerais presentes no sínter diminui na seguinte ordem:

Hematita > ferrita de cálcio > magnetita > Olivinas ( $\left.\mathrm{Mg}, \mathrm{Fe})_{2} \mathrm{SiO}_{4}\right)$.

Tanto a hematita quanto a magnetita são rapidamente reduzidas a wustita, mas as taxas de redução diferem na posterior redução de wustita a ferro puro. A partir da hematita, a wustita é reduzida rápida e homogeneamente, mesmo quando parte dela fica cercada de metal.

A partir da magnetita, a redução é topoquímica e quase todos os grãos são rapidamente cercados pelo metal que neste caso retarda futuras reações de redução Conforme salientado por Loo [14], o teor de FeO é utilizado como um indicador para os valores dos índices de redutibilidade e RDI [4].

De acordo com Malysheva [15] a redutibilidade do sinter é maior na faixa de basicidade compreendida entre1,5 e 2,3, conforme mostrado pela Figura 3.

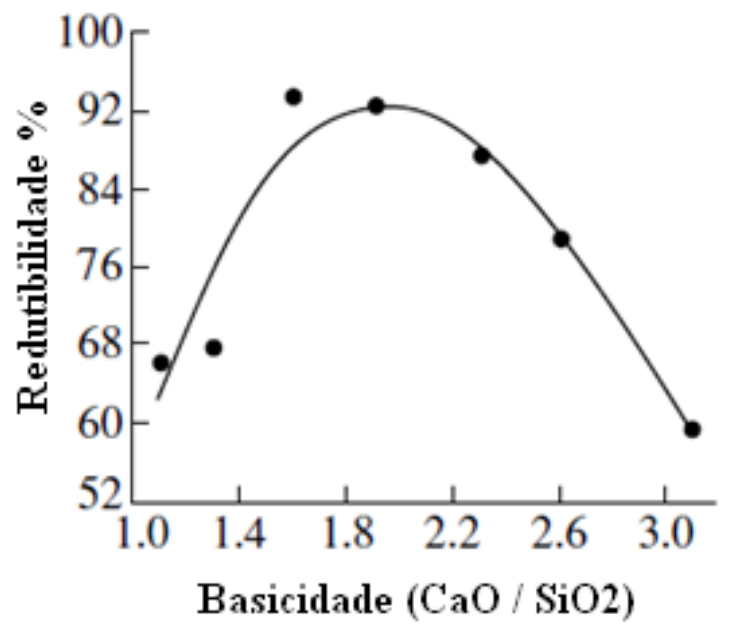

Figura 3 - Redutibilidade do sínter versus a basicidade [15]. 


\section{METODOLOGIA}

Foi necessário viabilizar uma estrutura para a instalação do equipamento.

Em decorrência do desenho do projeto, das alturas e dimensões de toda a aparelhagem que seria utilizada, construiu-se uma sala específica no Laboratório de Redução da CSN (Figura 4), para que o Forno de RI/RDI e o tambor de RDI fossem instalados.

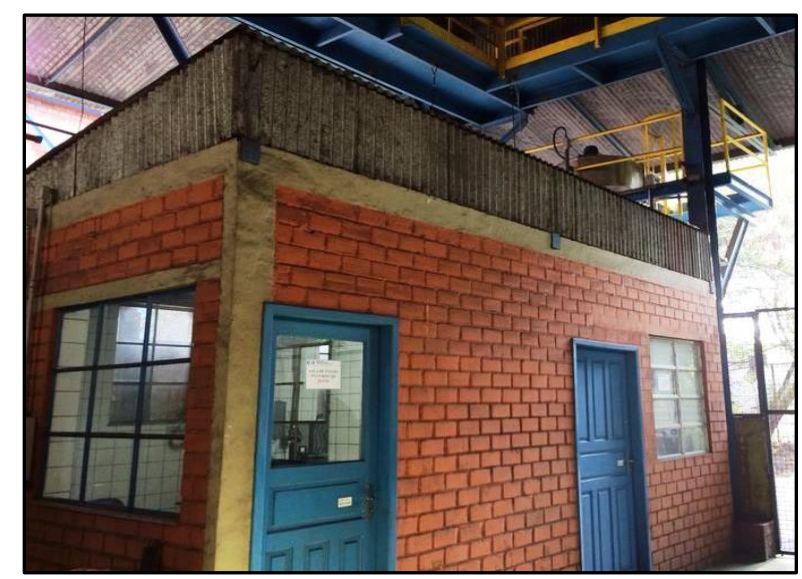

Figura 4 - Sala para ensaio de RI/RDI

A sala é dividida em duas sub-salas: de um lado fica a sala de controle (Figura 5), que contém o computador, o painel de controle do Forno RI/RDI, o painel do detector fixo do gás $\mathrm{CO}$ (monóxido de carbno), o ar condicionado para controle de temperatura dos equipamentos e a balança; na outra sub-sala, sala de ensaio (Figura 6), encontra-se isolado e com um excelente sistema de exaustão, o forno de RI/RDI, o tambor de RDI, o módulo de resfriamento da retorta e a mesa com todos os acessórios para a preparação da amostra.

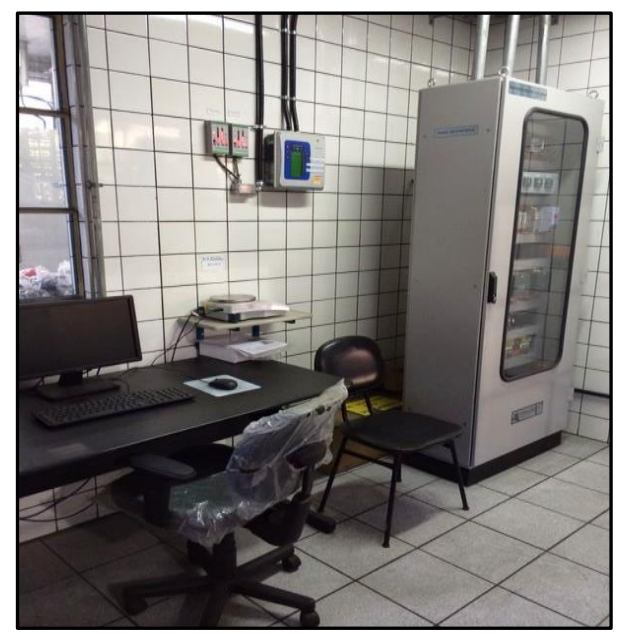

Figura 5 - Sala de controle

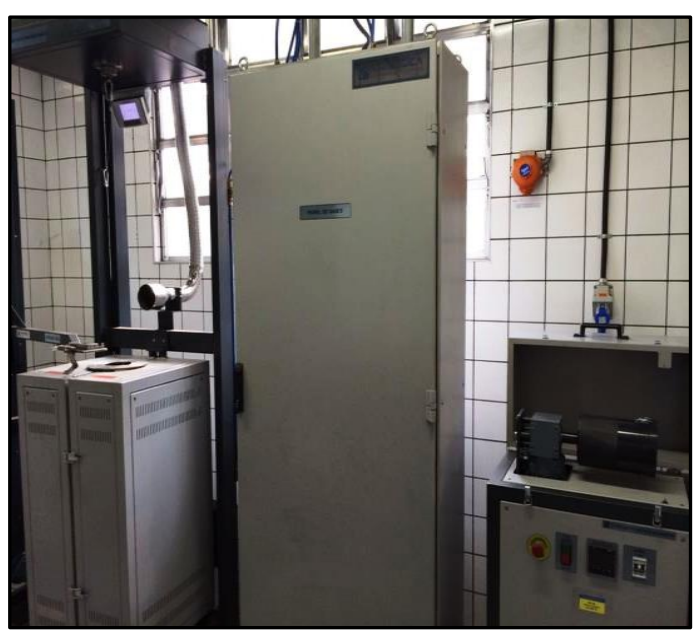

Figura 6 - Sala de ensaio

Em função da sala de RI/RDI ter sido construída muito próxima à rotas de pedestres, foi preciso também construir apanha enclausurada e com sistema de exaustão para 0 gás $\mathrm{CO}$, e outras apanhas, não vedadas, para os demais gases utilizados (Figura 7). Por hora, não foi comprada a norma ISO 4696-1, que utiliza também $\mathrm{CO}_{2}$ (gás carbônico) e $\mathrm{H}_{2}$ (hidrogênio) no ensaio para determinação de RDI, porém a apanha já está pronta para receber tais gases assim que a norma for adquirida. 

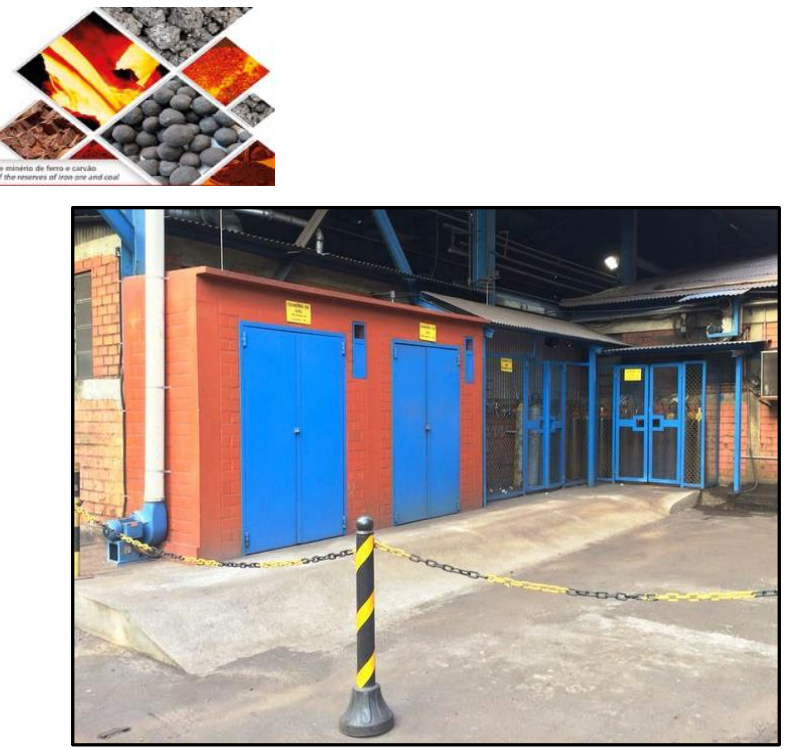

Figura 7- Apanha dos gases (CO e XX enclausurdos e com sistema de exaustão)

Acima da sala de ensaio, foi montado um excelente sistema de exaustão (Figura 8) que envia ao ambiente eventuais vazamentos dos gases sem danos à saúde do operador. Também considerando a saúde do operador, a sala de controle foi separada da sala de ensaio, e o operador carrega consigo um detector de $\mathrm{CO}$ portátil.

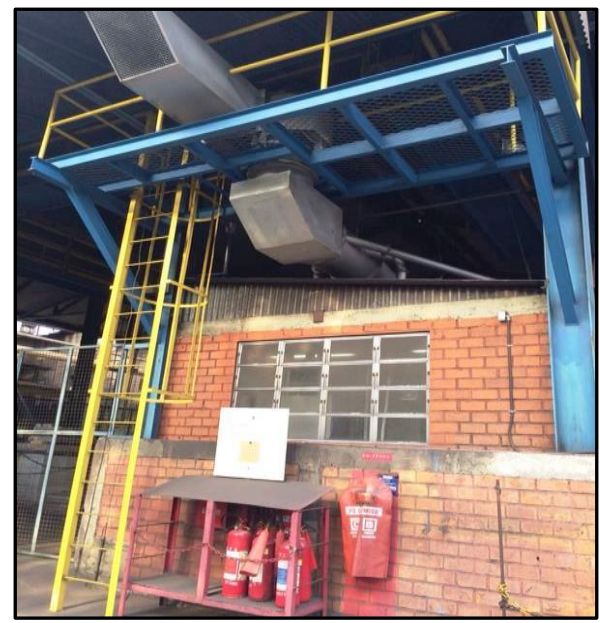

Figura 8 - Sistema de exautão

Por enquanto foram compradas três normas para ensaios de RI/RDI: ISO 4696-2, ISO 4695 e ISO 7215. E a fim de facilitar a rotina dos ensaios, as peneiras granulométricas, utilizadas para cada norma de ensaio, foram identificadas com cores diferentes (Figura 9). Desta forma evita-se consideravelmente possíveis erros na preparação da amostra e melhora-se ainda mais a confiabilidade dos ensaios.

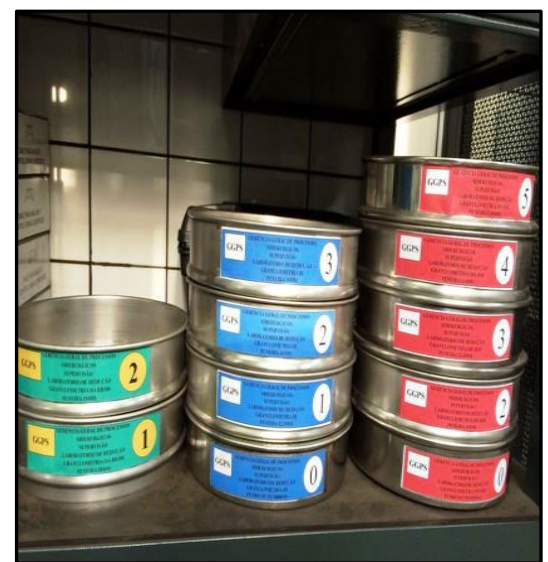

Figura 9 - Peneiras granulométricas diferenciadas por cor para cada Norma de ensaio adquirida

* Contribuição técnica ao 44 Seminário de Redução de Minério de Ferro e Matérias-primas, 
Após toda a instalação do equipamento e treinamento intensivo de operacionalização do forno e tambor de ensaio, foram confeccionados todos os Procedimentos Operacionais tanto de preparação das amostras, cada Norma possui uma preparação diferente, pois utiliza malhas diferentes do material a ser analisado, quanto da operacionalização do Forno. Após a inserção do material no forno para análise, todo o processo é automático, diferenciando somente na seleção de qual Norma de ensaio será realizada naquele momento.

Os Procedimentos Operacionais (Padrões Operacionais) adotados por todos os Laboratórios da Gerência Geral de Processos Siderúrgicos (GGPS) da CSN, são pictóricos, ou seja, cada etapa de preparação ou operacionalização dos equipamentos de cada análise, são ilustrados também com fotos (Figura 10) facilitando o entendimento e fixação da atividade por parte do operador.

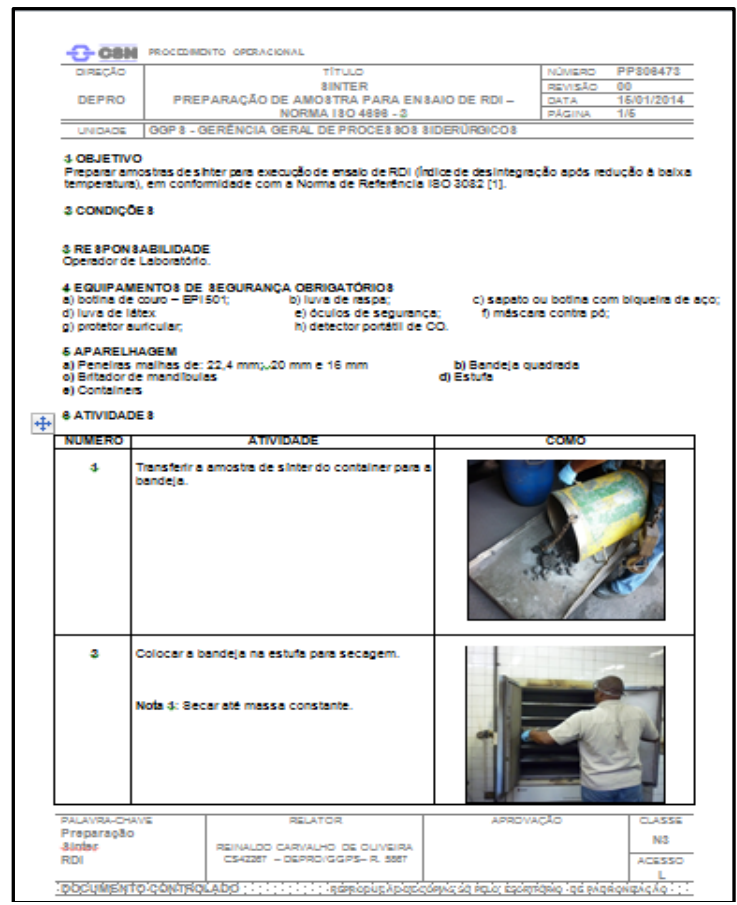

Figura 10 - Exemplo de Procedimento Operacional adotado pela CSN (Procedimento: Sínter Preparação de amostra para ensaio de RDI - Norma ISO 4694-2).

Abaixo, segue a tabela 2, contendo os tempos das etapas de cada Norma de ensaio, assim como o tempo total de cada ensaio, por Norma.

Tabela 2 - Tempo por etapa de ensaio e tempo total de cada ensaio, por Norma.

\begin{tabular}{|c|c|c|c|}
\hline ETAPAS & $\begin{array}{c}\text { RDI (ISO 4696-2) } \\
550^{\circ} \mathrm{C} \pm 5^{\circ} \mathrm{C}\end{array}$ & $\begin{array}{c}\text { RI (ISO 4695) } \\
950^{\circ} \mathrm{C} \pm{ }^{\circ} \mathrm{C}\end{array}$ & $\begin{array}{c}\text { RI180 (ISO 7215) } \\
900^{\circ} \mathrm{C} \pm{ }^{\circ} \mathrm{C}\end{array}$ \\
\hline Purga & $5 \mathrm{~min}$ & $5 \mathrm{~min}$ & $5 \mathrm{~min}$ \\
\hline Aquecimento & $90 \mathrm{~min}$ & $90 \mathrm{~min}$ & $90 \mathrm{~min}$ \\
\hline Estabilização & $15 \mathrm{~min}$ & $15 \mathrm{~min}$ & $15 \mathrm{~min}$ \\
\hline Redução & $30 \mathrm{~min}$ & $240 \mathrm{~min}$ & $180 \mathrm{~min}$ \\
\hline Resfriamento & $120 \mathrm{~min}$ & $120 \mathrm{~min}$ & $120 \mathrm{~min}$ \\
\hline Tempo ensaio & $\approx 4,5$ horas & $\approx 8$ horas & $\approx 7$ horas \\
\hline
\end{tabular}

Para a preparação das amostras, a granulometria para cada ensaio segue a Tabela 3.

* Contribuição técnica ao 44 Seminário de Redução de Minério de Ferro e Matérias-primas, 
Tabela 3: Granulometria das amostras para cada Norma adquirida

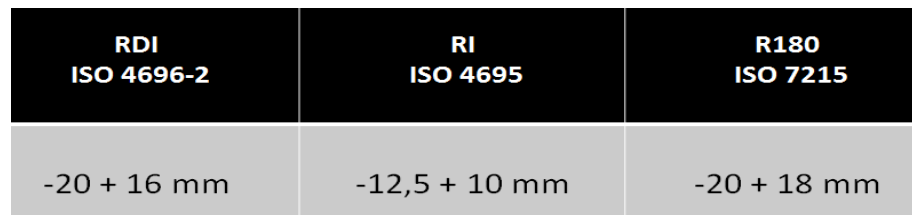

\section{RESULTADOS}

Por tratar-se de uma nova análise para os minérios dentro da CSN, por enquanto os levantamentos dos dados, para futuros projetos de melhoria do processo, estão restritos ao sínter. Porém, em breve começarão as análises para os demais tipos de minérios: pelotas, granulados, etc.

Na CSN constam três (3) máquinas sinterização, e o produto, sínter, de cada máquina, é nomeado Sínter 2, Sínter 3 e Sínter 4.

A Tabela 4 contém os dados para os ensaios de RDI (4696-2), para as três sinterizações existentes:

Tabela 4 - Resultados dos ensaios de RDI (Norma ISO 4696-2)

\begin{tabular}{|c|c|c|c|c|c|c|c|}
\hline \multicolumn{8}{|c|}{ ENSAIOS DE RDI - NORMA ISO 4696-2 } \\
\hline № & DATA & AMOSTRA & RDI (\%) & № & DATA & AMOSTRA & RDI (\%) \\
\hline 1 & $14 / 01 / 2014$ & Sinter 2 & 33,0 & 22 & $19 / 05 / 2014$ & Sinter 4 & 24,1 \\
\hline 2 & $15 / 01 / 2014$ & Sinter 4 & 26,1 & 23 & $21 / 05 / 2014$ & Sinter 3 & 23,7 \\
\hline 3 & $15 / 01 / 2014$ & Sinter 3 & 28,0 & 24 & $23 / 05 / 2014$ & Sínter 2 & 29,2 \\
\hline 4 & $16 / 01 / 2014$ & Sinter 2 & 27,0 & 25 & $26 / 05 / 2014$ & Sinter 4 & 27,3 \\
\hline 5 & $11 / 02 / 2014$ & Sinter 4 & 31,6 & 26 & $02 / 06 / 2014$ & Sínter 4 & 15,0 \\
\hline 6 & $16 / 03 / 2014$ & Sínter 4 & 24,8 & 27 & $09 / 06 / 2014$ & Sínter 4 & 21,2 \\
\hline 7 & $18 / 03 / 2014$ & Sínter 3 & 25,3 & 28 & $13 / 06 / 2014$ & Sinter 2 & 26,9 \\
\hline 8 & $20 / 03 / 2014$ & Sinter 2 & 26,5 & 29 & $20 / 06 / 2014$ & Sinter 2 & 17,7 \\
\hline 9 & $23 / 03 / 2014$ & Sinter 4 & 24,9 & 30 & $23 / 06 / 2014$ & Sinter 4 & 24,5 \\
\hline 10 & $25 / 03 / 2014$ & Sinter 3 & 25,2 & 31 & $26 / 06 / 2014$ & Sinter 3 & 20,8 \\
\hline 11 & $30 / 03 / 2014$ & Sinter 4 & 24,0 & 32 & $27 / 07 / 2014$ & Sínter 4 & 21,0 \\
\hline 12 & $01 / 04 / 2014$ & Sinter 3 & 28,4 & 33 & $30 / 06 / 2014$ & Sinter 4 & 26,1 \\
\hline 13 & $01 / 04 / 2014$ & Sinter 3 & 28,4 & 34 & $07 / 07 / 2014$ & Sínter 2 & 19,0 \\
\hline 14 & $03 / 04 / 2014$ & Sínter 2 & 25,1 & 35 & $07 / 07 / 2014$ & Sínter 4 & 32,5 \\
\hline 15 & $22 / 04 / 2014$ & Sinter 2 & 17,9 & 36 & $10 / 07 / 2014$ & Sinter 3 & 25,4 \\
\hline 16 & $24 / 04 / 2014$ & Sinter 3 & 29,8 & 37 & $21 / 07 / 2014$ & Sinter 4 & 18,6 \\
\hline 17 & $25 / 04 / 2014$ & Sínter2 & 28,4 & 38 & $23 / 07 / 2014$ & Sinter 3 & 25,2 \\
\hline 18 & $29 / 04 / 2014$ & Sinter 4 & 16,8 & 39 & $25 / 07 / 2014$ & Sinter 2 & 27,2 \\
\hline 19 & $05 / 05 / 2014$ & Sinter 4 & 13,3 & 40 & $28 / 07 / 2014$ & Sínter 4 & 27,9 \\
\hline 20 & $07 / 05 / 2014$ & Sinter 3 & 22,0 & 41 & $30 / 07 / 2014$ & Sinter 2 & 16,9 \\
\hline 21 & $14 / 05 / 2014$ & Sinter 3 & 17,1 & 42 & $04 / 08 / 2014$ & Sinter 4 & 29,8 \\
\hline
\end{tabular}

O ensaio de RDI (Reduction Degradation Index), resistência a quente, mede a degradação do sínter quando submetido às condições redutoras no alto-forno. Apesar de o sínter apresentar uma menor resistência que o minério e as pelotas, essa deficiência aparente é minimizada com um controle mais severo deste parâmetro, diminuindo-se a faixa de variação. Minério com alto índice de RDI não é adequado ao uso no alto-forno.

Já o ensaio de RI, indica a disposição do sínter em liberar o oxigênio pelo agente de

* Contribuição técnica ao 44 Seminário de Redução de Minério de Ferro e Matérias-primas, $\quad 15^{\circ}$ Simpósio Brasileiro de Minério de Ferro e 2ํㅗํ Simpósio Brasileiro de Aglomeração de Minério de Ferro, 15 a 18 de setembro de 2014, Belo Horizonte, MG, Brasil. 
redução. Procura-se manter este índice acima de 65\% e para isto é necessário que se controle a basicidade, o volume de escória e o teor de FeO.

Este índice indica que quanto maior for o seu valor, menor será o volume de escória primária gerada e maior a permeabilidade na zona coesiva dentro de um alto-forno.

A capacidade de redução das cargas metálicas está diretamente relacionada ao seu comportamento na zona coesiva. A intensidade de redução, à qual a carga é submetida, tem papel decisivo no processo de início de amolecimento. Portanto, é fundamental para o entendimento do comportamento da carga metálica a altas temperaturas, conhecer o seu grau de redução momentos antes de ter início o processo de amolecimento.

Abaixo segue a Tabela 5 contendo os valores, das três sinterizações, dos ensaios de $\mathrm{RI}$ :

Tabela 5 - Resultados dos ensaios de RI (Norma ISO 4695)

\begin{tabular}{|c|c|c|c|c|c|c|c|}
\hline \multicolumn{7}{|c|}{ ENSAIOS DE RI - NORMA ISO 4695 } \\
\hline No & DATA & AMOSTRA & RI (\%) & No & DATA & AMOSTRA & RI (\%) \\
\hline 1 & $13 / 02 / 2014$ & sínter 4 & 64,9 & 17 & $20 / 05 / 2014$ & Sinter 4 & 64,9 \\
\hline 2 & $14 / 02 / 2014$ & sínter 4 & 64,9 & 18 & $22 / 05 / 2014$ & Sínter 3 & 65,3 \\
\hline 3 & $18 / 02 / 2014$ & sínter 3 & 64,8 & 19 & $27 / 05 / 2014$ & Sinter 4 & 64,9 \\
\hline 4 & $19 / 02 / 2014$ & sínter 2 & 65,3 & 20 & $03 / 06 / 2014$ & Sinter 4 & 65,2 \\
\hline 5 & $16 / 04 / 2014$ & Sinter 4 & 64,8 & 21 & $10 / 06 / 2014$ & Sinter 4 & 64,5 \\
\hline 6 & $30 / 03 / 2014$ & Sínter 4 & 65,0 & 22 & $18 / 06 / 2014$ & Sínter 3 & 65,3 \\
\hline 7 & $01 / 04 / 2014$ & Sínter 3 & 65,7 & 23 & $24 / 06 / 2014$ & Sinter 4 & 65,1 \\
\hline 8 & $01 / 04 / 2014$ & Sínter 3 & 65,7 & 24 & $01 / 07 / 2014$ & Sinter 4 & 65,8 \\
\hline 9 & $06 / 04 / 2014$ & Sinter 4 & 64,9 & 25 & $08 / 07 / 2014$ & Sinter 4 & 66,2 \\
\hline 10 & $15 / 04 / 2014$ & Sinter 4 & 64,3 & 26 & $10 / 07 / 2014$ & Sínter 3 & 64,1 \\
\hline 11 & $24 / 04 / 2014$ & Sínter 3 & 65,0 & 27 & $14 / 07 / 2014$ & Sinter 4 & 64,7 \\
\hline 12 & $30 / 04 / 2014$ & Sinter 4 & 64,8 & 28 & $22 / 07 / 2014$ & Sinter 4 & 65,7 \\
\hline 13 & $06 / 05 / 2014$ & Sinter 4 & 65,5 & 29 & $24 / 07 / 2014$ & Sínter 3 & 64,8 \\
\hline 14 & $08 / 05 / 2014$ & Sínter 3 & 64,9 & 30 & $29 / 07 / 2014$ & Sinter 4 & 64,8 \\
\hline 15 & $13 / 05 / 2014$ & Sinter 4 & 65,0 & 31 & $31 / 07 / 2014$ & Sínter 3 & 65,3 \\
\hline 16 & $15 / 05 / 2014$ & Sínter 3 & 64,5 & 32 & $05 / 08 / 2014$ & Sinter 4 & 64,9 \\
\hline
\end{tabular}

Para validar o Forno de RI/RDI, instalado no Laboratório de Redução da CSN, e garantir a confiabilidade dos resultados, foram coletadas amostras das três sinterizações e enviadas a outras duas empresas, nomeadas de Empresa 1 e Empresa 2, afim de os resultados serem confrontados com os valores obtidos na CSN. Foi coletada quantidade de amostra suficiente para dividir entre as três empresas, ou seja, subdividiu uma mesma amostra em outras três (3).

O ensaio adotado para a validação do forno, e solicitado às outras duas empresas, foi o ensaio de RDI, segundo a Norma ISO 4696-2.

Os valores encontrados estão na Tabela 6 a seguir: 
Tabela 6 - Comparação de amostras de sínter, para as três sinterizações existentes na CSN, entre três empresas diferentes.

\begin{tabular}{|c|c|c|c|}
\hline \multicolumn{1}{|c|}{ AMOSTRA } & GRS\#2 & GSR\#3 & GSR\#4 \\
\hline 1 & 27,80 & 28,80 & 25,10 \\
\hline 2 & 28,50 & 25,40 & 30,60 \\
\hline CSN & 28,04 & 25,41 & 29,24 \\
\hline
\end{tabular}

Uma vez de posse de todos os resultados, os dados foram analisados e tratados estatisticamente, gerando a Tabela 7 abaixo:

Tabela 7 - Tratamento estatístico dos dados levantados com a comparação dos ensaios das três empresas

\begin{tabular}{|c|c|c|c|}
\hline \multicolumn{1}{|c||}{} & \multicolumn{3}{c|}{ Resultados de RDI (\%) } \\
\hline Empresa & S\#2 & S\#3 & S\#4 \\
\hline \hline 1 & 27,80 & 28,80 & 25,10 \\
\hline CSN & 28,50 & 25,40 & 30,60 \\
\hline Diferença CSN X 2 & 28,04 & 25,41 & 29,00 \\
\hline Diferença CSN X 1 & $\mathbf{0 , 2 4}$ & $-\mathbf{0 , 0 1}$ & $\mathbf{1 , 6 0}$ \\
\hline Média & $\mathbf{0 , 2 4}$ & $\mathbf{3 , 3 9}$ & $-\mathbf{3 , 9 0}$ \\
\hline Desvpad & 28,11 & 26,54 & 28,23 \\
\hline Máximo & 0,36 & 1,96 & 2,83 \\
\hline Mínimo & 28,50 & 28,80 & 30,60 \\
\hline \hline r\% Absoluto - ISO 4696-2 & 27,80 & 25,40 & 25,10 \\
\hline
\end{tabular}

\section{CONCLUSÃO}

Através da análise da Tabela 6 , tabela comparativa de resultados entre as três empresas, conclui-se que para um $r$ absoluto máximo de $5,30 \%$ esperado para os resultados obtidos, conforme especificado na norma ISO 4696-2, pode-se afirmar que as diferenças apresentadas entre resultados estão dentro da tolerância.

Sendo assim, pode-se confirmar a aceitação do teste comparativo realizado, e, por principal consequência, validar o equipamento do Forno de RI/RDI instalado no Laboratório da CSN.

E com os dados que estão sendo gerados, em breve a CSN estará realizando projetos para correlacionar os componentes do sínter (e de outras cargas metálicas) avaliando suas influências no produto, e, consequentemente, suas utilizações no alto-forno.

\section{REFERÊNCIA}

* Contribuição técnica ao 44ํㅗ Seminário de Redução de Minério de Ferro e Matérias-primas, 15 a 18 de setembro de 2014, Belo Horizonte, MG, Brasil. 
1 Jacomino VMF. et al. Controle ambiental das indústrias de ferro-gusa em altos-fornos a carvão vegetal, Belo Horizonte: Projeto Minas Ambiente, 2002.

2 Umadevi T. et al. Influence of Pellet Basicity $(\mathrm{CaO} / \mathrm{SiO} 2)$ on Iron Ore Pellet Properties and Microstructure. ISIJ International, 2011; 51(1): 14-20, 2011.

3 Susaki K. Fundentes e Escorificantes. Estudo Prospectivo do Setor Siderúrgico situação atual com tendências 2025. São Paulo: CGEE, 2008. 25p. [Nota técnica]

4 Lopes MV. Caracterização de Sínter de Minério de Ferro para Uso em Altos-Fornos a Carvão Vegetal. Dissertação de Mestrado, aprovada pela UNIFEI, Itajubá, Dezembro, 2012, 99 p.

5 Mourão JM. Estudo Prospectivo do Setor Siderúrgico: 2008-2025. Brasília: Centro de Gestão e Estudos Estratégicos, 2008. 50p. [Nota técnica].

6 Lankford WT Jr., Samways NL, Craven RF, Mcgannon HE. The Making, Shaping and Treating of Steel, 10.ed., Pittsburgh (USA): The AISE Steel Foundation, 1985. cap.5, p.304-312.

7 Mourão MB. (coord.). Introdução a Siderurgia, São Paulo: Associação Brasileira de Metalurgia e Materiais, 2007.

8 Dawsan, PR. Recent Developments in Iron Ore Sintering - Part 1 Introduction. Ironmaking and Steelmaking. 1993;20(2):135-136.

9 Oliveira ER; Martins J. Emprego de resíduos siderúrgicos e pellet feed minipelotizados na sínterização de minério de ferro. Revista Escola de Minas, Ouro Preto, 2003, 56(4): 249-254.

10 Cassola MS, Moraes SL. Aspectos tecnológicos do efeito de aglomerantes na microestrutura de Pelotas de concentrados de minério de ferro. Revista Metalurgia e Materiais da ABM, v. 63, setembro de 2007, São Paulo, Brasil.

11 Vieira $C B$ et al. Avaliação técnica de minérios de ferro para sínterização nas siderúrgicas e minerações brasileiras: uma análise crítica. Revista Escola de Minas. 2003;56(2):97102.

12 Pereira HC. Avaliação em escala piloto do comportamento dos produtos pellets feed, pellet screenings e micro pellet em substituição ao sínter feed em uma mistura de sinterização [Dissertação Mestrado em Engenharia Metalúrgica e de Minas]. Belo Horizonte: Universidade Federal de Minas Gerais; 2004.

13 Dawsan, PR. Recent Developments in Iron Ore Sintering - Part 2: Research studies on sintering and sinter quality. Ironmaking and Steelmaking. 1993;20(2):137-143.

14 Loo CE. Some progress in understanding the science of iron ore sintering. In: ICSTI Ironmaking conference proceedings; 1998. p.1299-1316.

15 Malysheva TY, Yusfin YuS, Mansurova NR, Gibadulin MF, Lekin VP. Mechanism of Mineral Formation and Metallurgical Properties of Sinter of Basicity 1.1-3.1 at OAO MMK. Steel in Translation. 2007;7(2):126-130. 